\title{
TÉCNICA MISTA (IONÔMERO DE VIDRO/RESINA COMPOSTA) PARA UMA RESTAURAÇÃO DE CLASSE $V$
}

\author{
FÁTIMA CRISTINA DE SÁ 1 \\ RAUL SANTOS DE SÁ2 \\ JOÄO BATISTA DE SOUZA ${ }^{3}$
}

\begin{abstract}
SÁ, F.C. de; SÁ, R.S. de; SOUZA, J.B. de. Técnica mista (ionômero de vidro/resina composta) para uma restauraçắo de classe V. Semina: Ci. Biol./Saúde, Londrina, v. 14, n. 2, p. 105-111, jun. 1993.
\end{abstract}

RESUMO: Os autores objetivam uma revisão da literatura, sobre as indicaçōes e as principais vantagens dos cimentos de ionómero de vidro, assim como, relatar os methores resultados da Técnica Mista ou Técnica do Sanduiche, ou seja, da associaçáo do ionômero de vidro com a resina composta. Descrevem ainda, a seqüência clf́nica do preparo e restauraçăo de Classe $V$ usando essa técnica.

PALAVRAS-CHAVE: Técnica de Sandúche; Cimento de lonomero de Viơro; Resina Composta.

\section{1 - INTRODUÇĀO}

A Dentística Restauradora tem por finalidade reproduzir a forma, função e estética e proteger adequadamente o órgão pulpar dos dentes com perda de estrutura e para tanto, baseia-se em princípios mecânicos e biológicos que procuram adaptar as características físicas e químicas inerentes à cada material restaurador aos preparos de cavidades.

Antes da introduçäo das resinas acrilicas para restauraçäo na Odontologia, nos idos de 1940, o único material restaurador existente pela técnica direta, era o cimento de silicato. Este material constituído de partfculas de vidro sflico, envolvidas por uma matriz complexa de gel orgânico, foi usado por cerca de 80 anos. Portanto, o material restaurador estético mais longamente usado foi o cimento de silicato. Com o advento das resinas acrílicas este material começou a ser utilizado em restauraçōes odontológicas em dentes anteriores, com resultados pouco satisfatórios.

Porem, as pesquisas näo pararam e BOWEN apud POLETTO, 1988, observando que o principal problema das resinas acfílicas era a contraçāo de polimerização, descobriu em 1962, que ao unir uma resina epóxica, que por conter uma molécula maior possufa uma menor contração de polimerizaçāo, com uma resina acrílica que tinha a rapidez para a polimerização, poderia aproveitar as propriedades de cada uma delas. Bowen assim o fez e esta uniāo formou o composto denominado de BIS-GMA e para melhorar suas propriedades, foi incluída uma porcentagem de partículas inorgânicas. Este composto cons- titúdo de uma matriz orgânica e cargas inorgânicas unidas por um agente de uniāo foi denominado de resina composta.

A busca de um material restaurador ideal tem motivado pesquisadores e fabricantes a desenvolver novos produtos de modo a obter restauraçōes que apresentem uma adesão físico-quimica à estrutura dentária, tenham estabilidade dimensional e ausênca de infiltraçẩo marginal. Em adiçăo a todos estes requisitos, a restauração deve possuir biocompatibilidade, reproduzir a cor natural do dente e restabelecer sua forma e funçäo.

Assim, WILSON \& KENT, em 1971, apresentaram o cimento de ionómero de vidro, que pode ser considerado um híbrido entre o cimento de policarboxilato e de silicato, pois possui composição do pó semelhante à do silicato e do líquido semelhante à do policarboxilato. Este material tem capacidade de ceder lons flúor às estruturas dentárias tal como o cimento de silicato e ainda se unir quimicamente à dentina e esmalte como o policarboxilato.

O cimento de ionômero de vidro foi proposto inicialmente, para restaurar lesōes do tipo Classe III, dentes que sofreram erosão, abrasão, como material de cimentaçäo ou como agente de forramento de cavidade (WILSON \& KENT, 1972).

Esse cimento tem sido estudado intensamente através de pesquisas clínicas e laboratoriais e suas qualidades têm sido melhoradas consideravelmente.

MCLEAN et al (1985), na tentativa de melhorar a retençāo das restauraçōes com resina composta, reduzir a infiltração marginal e acabar com os efeitos indesejá-

1 - Departamento de Odontologia Restauradora/Centro de Ciências da Saúde - Universidade Estadual de Londrina. Caixa Postal, Eoo1, CEP 86051-970, Londrina-Paraná - Brasil

2 - Departamento de Odontologia Restauradora/Centro de Cièncias da Saúde - Universidade Estadual de Londrina. Caixa Postal, 6001, CEP 86051-970, Londrina-Paraná - Brasil

3 - Departamento de Reabilitação Oral - Faculdade de Odontologia - Universidade Federal de Goiás. Caixa Postal, 131, CEP 74001-970, Goiânia-Goiás - Brasil 
veis do sistema agente de união/resina composta sobre a dentina, recomendaram uma técnica mișta para a restauração de dentes anteriores, em que utilizaram vários tipos de cimentos ionoméricos como agentes forradores dentinários. Após 5 minutos da inserção na cavidade, os cimentos eram desgastados superficialmente e eram submetidos ao condicionamento ácido por 60 segundos (fosfórico a $37 \%$ ). Em seguida, era feita a aplicaçāo do agente de união e realizada a restauração de resina composta.

Estes autores foram os precursores da Técnica Mista (ionómero/resina), também chamada de técnica de "sanduíche", porém este trabalho tem por finalidade abordar, através de uma revisäo bibliográfica, outros autores que contribufram para as pesquisas e os avanços relacionados ao assunto e descrever a seqüência clinica para uma restauração de Classe $V$ pela técnica acima citada, justificando todos os passos clínicos e evidenciando as vantagens dessa associaçāo.

\section{2 - CONSIDERAÇŌES GERAIS}

As indicaçōes para o cimento de ionômero de vidro sāo muitas. Podemos mencionar:

- cavidades de classe III (especialmente aquelas que nāo se estendam para a superfície vestibular e aquelas com acesso pela face palatina que não coincidem com áreas de contato proximal e/ou dente antagónico):

- cavidade de Classe $V$ llesão cariosa e erosão/abrasão):

- restauraçöes preventivas em cavidades de Classe 1 (oclusais) incipientes;

- cobertura de emergência em dentes anteriores fraturados:

- cavidade tipo "túnel";

- selamento de cicatriculas e fissuras;

- cavidades de Classe I e ll em dentes decíduos;

- como material para núcleo de preenchimento;

- como material cimentante para restauraçōes metálicas fundidas (BARATIERI et al, 1989).

Dentre as indicaçōes, não podemos deixar de ressaltar, ainda, sua açāo como agente intermediário (base forradora) em restauraçöes a amálgama e, principalmente, às resinas compostas por apresentar adesāo flsico-química' às estruturas dentárias (BARATIERI et al, 1989). As caracteristicas do ionómero de vidro como biocompatibilidade, liberaçāo de flúor, adesividade e integridade marginal são, excelentes, entretanto, eles são sempre deixados como escolha secundária para restauraçōes de dentes anteriores e posteriores. Por outro lado à semelhança dos cimentos de silicato, o ionômero de vidro está sujeito ao fenômeno denominado de sorpçâo, no qual o material, dependendo do meio ambiente em que se trabalha, pode perder ou absorver água, acarretando alteração de suas propriedades. A água ocupa parte do volume do gel, que em ambiente seco pode perder esta água por evaporação em sua superfície, por um processo denominado de sinérese. Em ambiente úmido, pode ocorrer a absorção de água, processo esse denominado de embebição. Quando o material é utilizado sozinho em restauraçôes, deve ter sua superfície imediatamente protegida por verniz, para evitar o aparecimento de sinérese ou embebição. Presa demorada, opacidade, baixa resistência de bordos e ao desgaste, pobre acabamento, falta de translucidez confere ao cimento de ionômero de vidro essas desvantagens, quando comparado às resinas compostas. Estas säo mais fáceis de trabalhar, manusear, manipular e permitem bom acabamento e polimento e são esteticamente aceitáveis. \{SUZUKI \& JORDAN, 1990).

A restauraçāo combinada ionômero de vidro/resina composta (Técnica de "Sanduiche") providencia uma forte adesão qưlmica à dentina, adesāo micromecânica da resina composta à superfície do ionômero, um resultado estético aceitável, além de diminuir a sensibilidade pósoperatória e reduçăo volumétrica da resina composta, com menor contraçäo de polimerização. (SUZUKI \& JORDAN, 1990).

Esta associação ê particularmente útil onde a estética é de suma importância. As resinas compostas modernas são reconhecidas como o material restaurador mais estético atualmente. A técnica do condicionamento ácido permite que elas se unam ao esmalte com uma estrutura prismática bem definida. Entretanto, a falta de efetividade do selamento marginal pode ser afetada pela posição anatômica e condiçōes estruturais da superffcie de esmalte dental. $O$ esmalte cervical é mais fino e mais irregular em estrutura prismática e a superfície pode estar destituída de marcaçōes prismáticas características. O selamento marginal pode ser estabelecido pelo condicionamento das paredes de esmalte mais grossas e biseladas na incisal e áreas do corpo do dente, mas as lesôes cariosas de Classe $\mathrm{V}$ e cáries que se estendam para a dentina ou áreas com falta de esmalte na cervical apresentam um dos maiores problemas: a microinfiltração pode atacar a dentina. Usando adesivo dentinário nem sempre diminui o problema. O uso do cimento de ionômero de vidro sela estas áreas dentinárias solucionando o problema.

Objetivando apresentar as vantagens desta associação, ê de fundamental importância que seja descrita a seqüênca clínica para uma restauração de Classe $V$ pela Técnica Mista (ionômero/resina), onde serāo justificados os passos clínicos.

A Técnica Mista, também chamada de Técnica de "Sanduíche", preconizada, inicialmente, por McLEAN et al (1985) e divulgada por vários autores, associa as boas propriedades dos cimentos ionoméricos como adesividade e biocompatibilidade com as das resinas compostas.

Apesar de ter sido, inicialmente, idealizada para aquelas cavidades que nāo apresentam esmalte na margem cervical, como por exemplo aquelas lesōes de erosão/abrasäo, pode, tambếm ser empregada em todos os tipos de cavidades a serem restauradas com resinas compostas (BARATIERI et al, 1989). A resina composta e selecionada e a cor é escolhida. $O$ campo operatório de-

Semina, Ci. Biol.JSaúde, v. 14, n. 2, p. 105-111, jun. 1993 
verá ser adequadamente isolado com dique de borracha para que a umidade não altere as propriedades dos materiais utilizados. Os grampos números 212 (HU Friedy) e B-6 retrator (Hygienic) são os melhores para retração gengival na região anterior e de pré-molares, enquanto o número 210 é usado para a região de molares. É aconseIhável, neste caso, anestesiar a regiāo do dente a ser restaurado, para conforto do paciente, durante as manobras de colocaçāo e estabilização do grampo.

A remaçăo da cárie deverá ser realizada, se necessário, com brocas esféricas girando em baixa velocidade.

Se o caso exigir, um preparo de Classe $V$ convencional é realizado. As margens de esmalte desorganizado, devem ser biseladas para aumentar a área para a uniāo com a resina composta.

A limpeza da superffcie da lesão é muito importante. Para se obter a máxima adesão entre os cimentos ionoméricos e a estrutura dental e os benefícios advindos da mesma, é necessário que a cavidade seja adequadamente limpa e seca. Limpar, sob estas circunstáncias, significa a remoçâo da placa e da película adquirida, assim como da dentina e esmalte desorganizado e outros detritos grosseiros que recobrem a superfície dessas lesỏes. Entretanto, é necessário reter todos os fons cálcio possiveis, tanto no esmalte como na dentina. Para tal, a limpeza deve ser executada em duas etapas:

1. através de uma pasta de pedra pomes e água, a qual deve ser aplicada com taças de borracha, sendo, em seguida, lavada com água e seca com ar:

2. numa segunda etapa, a limpeza deve ser refinada através do emprego de um ácido fraco, como o ácido poliacrílico $25 \%$, que deve ser aplicado durante 10 segundos sobre a superficie da lesâo. A seguir, a mesma deverá ser, novamente, lavada com água e seca com ar (BARATIERI et al, 1989). Segundo POWIS et al (1982), este procedimento possibilita um aumento considerável na força de uniảo dos cimentos ionoméricos com a estrutura dental, sem, contudo, acarretar qualquer prejuizo para o órgão pulpar. Deve-se, salientar, também, que a retenção dos cimentos ionoméricos não é obtida através da penetração do material dentro dos túbulos dentinários.

Se a cavidade for considerada profunda (com menos de $0,5 \mathrm{~mm}$ de dentina remanescente), antes do cimento de iqnômero de vidro é conveniente que se aplique uma fina camada de cimento de hidróxido de cálcio. Cuidado especial deverá ser tomado para que a camada de cimento fique bem fina, aproximadamente $0,5 \mathrm{~mm}$ de espessura, para evitar que ele, por transparência, prejudique a estética da restauração. Da mesma forma, é importante a seleção de um cimento ionomérico que apresente a cor aproximada da dentina.

Em seguida, faz-se a manipulação do ionômero de vidro selecionado, de acordo com as determinaçōes do fabricante. Este ionômero será aplicado sobre todas as paredes de dentina. Quando a cavidade näo apresentar esmalte na margem cervical, o cimento ionomérico deverá ser estendido até o ângulo cavo-superficial gengival.

Após a inserção do cimento, ele deverá ser deixado em repouso por, no mínimo, cinco minutos, para que ocorra a sua presa nicial. Porem, sempre que posslvel, deve-se aguardar mais tempo (15 minutos) para que se proceda o condicionamento ácido da superfície do cimento ionomérico, uma vez que, à medida que o cimento vai tomando presa (amadurecendo), torna-se mais adequado para o condicionamento seletivo da matriz. Nesse sentido, algumas vezes, poderá ser estratégico restaurar a cavidade numa sessāo com cimento ionomérico e com plementar o procedimento restaurador com resina composta em outra sessāo (BARATIERI et al, 1989).

O passo seguinte ê realizar o condicionamento ácido do esmalte biselado e da superfície do cimento ionomérico. Emprega-se o ácido fosfórico a $37 \% \mathrm{em}$ gel ou em líquido, mas de preferencia em gel para termos um maior controle de zonas de aplicaçäo. Deve-se aplicá-lo, primeiramente, no esmalte e cemento por 15 segundose só após esses 15 segundos, apliç-lo sobre a superificie do ionômero por mais 15 segundos, para que seja completado o tempo de 30 segundos. Lavamos toda a superfície com um spray ar/água durante 20 segundos se foi aplicado um ácido em soluçâo e durante 60 segundos, se em gel.

Este condicionamento ácido na superfície dos cimentos de ionómero de vidro, possibilita a criaçāo de microporosidades que permitem uma forte união entre eles e as resinas compostas. Mais modernamente, porém. mercé de novas pesquisas, este último procedimento tem sido eliminado, ou seja, tem sido descartado o condicionamento ácido do ionômero.

Após o condicionamento ácido do esmalte e superfície do cimento ionomérico, uma fina camada de um adesivo dentinário ou mesmo de um adesivo para esmalte deverá ser aplicado sobre a área condicionada. Os excessos de adesivo deverão ser eliminados com um suave jato de ar e em seguida a polimerização é feita com luz visivel por 20 segundos. A resina composta selecionada, que poderá ser uma de micropartículas, será inserida em pequenas porçōes e cada porção será fotopolimeriza da por 20 segundos. A restauração só deverá ser acabada e polida, no minimo, 24 horas após com brocas carbide de 12 ou 16 lâmiras e pontas diamantadas da sêrie F e FF (KG Sorensen), completando o procedimento usando taças de borracha abrasiva próprias para resina composta e pedras montadas de $\delta$ xido de alumínio.

Após o polimento, 20 segundos mais de incidência de luz para polimerizar e recomendada para assegurar que o máximo de monômeros convertidos seja conseguido.

As restauraçôes executadas através desta técnica, além de apresentarem as vantagens atribuídas aos cimentos ionoméricos e às resinas compostas, ostentam menor grau de infiltração marginal, principalmente na interface cemento/dentina/restauraçăo, evitando o desenvolvimento de cárie secundária e consequentemente uma patologia pulpar (BARATIERI et al, 1989; MOUNT, 1989a; MOUNT, 1990; SUZUKI \& JORDAN, 1990 ). 


\section{RESTAURAÇÄO COM CIMENTO DE IONÔMERO DE VIDRO FOTOPOLIMERIZÁVEL}

Os cimentos de ionómero de vidro fotopolimerizéveis têm eliminado muito as deficiências de manipulação dos cimentos ionoméricos tradicionais e tem quase feito dos ionómeros que tomam presa quimicamente um material obsoleto. Facilidade de manipulaçăo, resistência ao desgaste e aumento da adesão à dentina são algumas das vantagens dos cimentos de ionômero de vidro fotopolimerizáveis. Entretanto, para preparos cavitários profundos, próximos da polpa, a aplicação de uma pequena quantidade de cimento de hidróxido de cálcio é ainda recomendada.

Um cimento de ionómero de vidro para forramento é misturado de acordo com as recomendaçōes do fabricante (VITRABOND, 3M] e aplicado sobre a superficie dentinária, até próximo da margem da futura restaura. ção. Como o ionômero de vidro é relativamente opaco e a resina composta um material translucente, o ionômero irá brilhar através da resina composta se for levado atê a margem da restauraçäo.

Quando se usa um cimento de ionômero de vidro para forramento fotopolimerizável, o condicionador dentinário (ácido poliacrílico $25 \%$ ) näo é necessário.

Após a polimerizaçāo com luz visivel por 30 a 40 segundos, o esmalte do ângulo cavo-superficial é biselado com ponta diamantada de ponta ativa de formato arredondado. Então um ácido fosfórico a $37 \%$ em forma de gel é cuidadosamente aplicado no esmalte do ångulo cavo-superficial por 30 segundos utilizando-se uma serin$\mathrm{ga}$, pois consegue-se confinar o ácido somente no local desejado.

Com o cimento de ionômero de vidro fotopolimerizável, o condicionamento do ionômero, já polimerizado, com ácido fosfórico nāo é necessário para se estabelecer a união com a resina composta que o recobrirá. Lava-se a lesão com água por 15 segundos e seca-se com jatos de ar. A dentina da periferia não coberta pelo forramento de ionômero deve ser tratada com o Primer (SCOTCHBOND 11, $3 \mathrm{M}\}$ por 60 segundos. Em seguida, um agente de união fotopolimerizável é aplicado sobre toda a área e polimerizado com luz visível por 30 a 40 segundos. A camada do agente de uุnião inibida pelo ar deverá ser removida. A resina composta $e$ colocada com um instrumento plástico ou metálico.

Em lesōes cervicais grandes, utiliza-se o sistema de aplicaçăo de resina por incrementos para minimizar a contração de polimerização; onde a têcnica de colocaçāo da resina é à mão livre, moldando, ou melhor, devolvendo o contorno anatômico do dente que está sendo restaurado. A fotopolimerização é feita em 40 segundos, os excessos grosseiros sảo removidos com brocas de acabamento carbide multilaminadas. As garras do grampo que foi usado para o isolamento absoluto do campo operatório, devem ser levadas a $0,5 \mathrm{~mm}$ para apical para permitir um correto acabamento da margem gengival da restauração. O contorno final da restauraçäo é dado com discos de oxido de alumínio (DISCOS SOFLEX, 3M] (SUZUKI \& JORDAN, 1990). (Ver figura no final do texto)

\section{3 - REVISĀO DA LITERATURA}

WILSON \& KENT (1972) relataram que a reaçäo de presa do cimento de ionômero de vidro é essencialmente uma reação ácido/base, que ocorre entre o pó e o Ifquido formando-se um sal hidratado. A reatividade do pó depende da reação entre a alumina e a sílica, já que a reação entre os dois óxidos e determinante para tornar o vidro mais ou menos básico. Como a reaçäo é ácido/básica, quanto mais básico for o pó, maior será a velocidade da reaçăo. Na pasta recêm misturada, presume-se que prótons hidratados do lfquido penetram nas regiōes superficiais das partículas de $p \delta$, desiocando os cátios $\left(\mathrm{Ca}^{++} \mathrm{e}\right.$ $\mathrm{Al}^{++}$) e degradando a trama aluminosilicato de um gel silicoso hidratado. Cátions simples ou como complexos de fluoretos migram na fase aquosa de pasta de cimento onde pontes de sais metálicos são formados entre as cadeias longas de fons policarboxilato carregados, interligando-se e causando a geleificação da fase aquosa e o endurecimento do cimento em uma massa amorfa.

TOBIAS et al (1978) realizaram um estudo em dentes humanos e em animais. Após preparo convencional de Classe 1 , restauraram as cavidades com ASPA. Ao final da pesquisa, os autores não observaram, em nenhum caso, formaçāo de dentina reparadora. Nos primeiros 10 dias, ocorreu reduçăo do número de odontoblastos e infiltrado inflamatório que diminúa com o tempo. Foram feitos exames após 30 dias e alguns dentes apresentavam células inflamatórias dispersas. Sendo assim, baseados nos resultados da pesquisa, os autores só recomendam o ASPA como agente de forramento em cavidades rasas. $\mathrm{Em}$ cavidades profundas recomendam uma base de hidróxido de cálcio prévia ao cimento de ionômero de vidro.

A AMERICAN DENTAL ASSOCIATION (1979) através do Conselho de Materiais Dentários e Equipamentos, publicou o seu parecer sobre o estágio atual dos cimentos de ionômero de vidro, onde determinam que a causa mais comum de falhas de restauraçöes com ionômero de vidro e o proporcionamento e mistura (manipulaçăo) incorretos do material. A mistura deve ter a consistência parecida com massa de vidraceiro e deve ter, ainda, uma aparência brilhante para assegurar que suficientes grupos de ácidos carboxílicos livres estejam presentes para proporcionar adequado umedecimento da superficie da cavidade. Para que se efetue uma uniâo adesiva, um molhamento adequado da superficie dental $e$ essencial.

CHARBENEAU \& BOZELL (1979) apontaram que, provavelmente, a mais notável característica destes cimentos é seu potencial de adesāo, nāo somente ao esmalte, mas, também à dentina através de ligaçōes polares iônicas - adesāo físico-química. Os autores também fizeram algumas consideraçöes clínicas. Relataram que as misturas consistentes de cimento de ionômero de vidro 
năo săo facilmente obtidas quando o proporcionador póIfquido é utilizado. Isto é comprovado em algumas das falhas precoces de retençāo, em pesquisas clinicas. As cápsulas pré-pesadas e a mistura mecánica parecem produzir uma consistência adequada para manusear convenientemente e para se conseguir adesão.

KAWAHARA, IMANISHI \& OSHIMA (1979) realizaram um estudo comparativo da biocompatibilidade dos cimentos ionoméricos Fuji lonomer e Aspa com os cimentos de policarboxilato e óxido de zinco e eugenol, utilizando a cultura de tecidos e observando a resposta pulpar, em macacos. Uma vez realizados os testes, tanto com o cimento nāo endurecido como após sua presa, os resultados foram comparados com os cimentos de policarboxilato e óxido de zinco e eugenol.

Durante a reação de presa, os dois cimentos de ionômero de vidro apresentaram uma leve citotoxicidade em relação aos outros cimentos que foram utilizados nos testes. Esta citotoxicidade foi ainda menor após a presa, praticamente desapareceu. Já que os componentes do pó não citotóxicos, o principal fator da discreta reação durante o processo de endurecimento, é a soluçāo aquosa do ácido poliacrílico. A reação pulpar que ocorre após a aplicaçāo do cimento de ionômero de vidro como protetor pulpar direto nåo é diferente da provocada pelo uso do cimento de $\delta x i d o$ de zinco e eugenol. Baseados nesta pesquisa, os autores concluíram que estes cimentos podem ser utilizados como capeador pulpar e obturador do canal radicular e será amplamente utilizado graças à sua biocompatibilidade.

MONDELLI et al (1984) evidenciaram o cimento de ionơmero de vidro como um material em evoluçâo, porêm, o uso, viabilidade e procedimentos técnicos não foram totalmente esclarecidos, apesar das pesquisas laboratoriais e controles clínicos realizados. Estas pesquisas revelam, através dos seus resultados, entretanto, que este material poderá no futuro ocupar um lugar de destaque dentre os materiais restauradores estéticos.

Selamento de fóssulas e fissuras, restauraçöes de dentes decíduos, cavidades de Classe III e $V$ e restauraçōes de erosão, são algumas das indicaçōes do cimento de ionómero de vidro, graças à sua natureza hidrofílica e a capacidade de adesão à estrutura dentária. Como contra-indicaçōes temos as restauraçōes de Classe 11 , reconstrução de cúspides, cavidades extensas de Classe V de dentes anteriores, grandes áreas vestibulares e restauraçōes de Classe IV, pois possui baixa resistência à tração e baixa translucidez.

Segundo CHIN \& TYAS (1988), ef evidente que os cimentos de ionómero de vidro são passiveis de serem condicionados pelos condicionadores de esmalte convencionais, os quais produzem uma superficie apropriada para reter mecanicamente a resina composta.

Utilizaram 4 tipos de ionĉmero de vidro para realizar um estudo laboratorial a fim de determinar a resistência à traçäo de 3 cimentos de ionômero de vidro após o condicionamento. A resistência à tração da dentina não tratada esteve entre $4,47-5,52 \mathrm{MPa}$, sendo aproximada- mente 2 vezes aquela do cimento ionomérico tipo restaurador. Após o condicionamento do cimento de ionómero de vidro, a resistência à tração da resina composta foi para 1,83 a $6,17 \mathrm{MPa}$, dependendo do ionômero e do tempo após a mistura, o qual ele foi condicionado. $\mathrm{Na}$ maioria das situaçóes clinicas, retençăo da restauração de resina composta pelo cimento de ionómero de vidro necessitaria, provavelmente, ser complementada por retenção mecânica adicional.

SHETH et al (1989) compararam "in vitro" a resistência à tração e à microinfiltração da resina composta aos cimentos de ionómero de vidro condicionados e nāo condicionados. Compararam, também, a resistência à fratura coesiva de cada cimento para determinar se o processo de condicionamento contribuiu significativamente ao resultado de uniāo da resina com o cimento. Os resultados deste estudo nâo demonstraram nenhuma diferença significante na resisteencia à tração entre a resina composta e o cimento de ionómero de vidro condicionado e o não condicionado. A microscopia eletrónica de varredura revelou ser, a superficie näo condicionada, topograficamente quase täo retentiva como uma superflcie condicionada. Estes resultados sugerem que não há necessidade de se condicionar o cimento de ionômero de vidro antes da restauração com resina composta. A ausência de diferenças na microinfiltração entre os dois grupos reforça esta conclusāo.

PORTO NETO et al (1990) decidiram avaliar a superficie de corpos de prova de cimento de ionômero de vidro condicionados e nāo condicionados por ácido fosfórico $37 \% \mathrm{em}$ forma de gel ou Ifquido, no seguintes intervalos de tempo: 15,30 e 60 segundos de condicionamento, pois baseados em um estudo de SMITH (1988), tempos mais curtos de condicionamento ácido podem reduzir a dissoluçâo da matriz de ionómero de vidro e a penetração do ácido nos túbulos dentinários. A microscopia eletrônica de varredura foi empregada para avaliar o comportamento das superfícies estudadas. Utilizaram o Ceram Fil (DFL), o Ceram Lin (DFL) e Vitrabond (3M). Os testes foram realizados e as fotomicrografias obtidas revelaram rápida deterioração da superfície dos cimentos testados aos 30 de 60 segundos de condicionamento acido. Os ácidos em forma de gel ou líquido atuaram com a mesma velocidade de deterioração sobre a superfície dos cimentos. É aconselhável limitar o condicionamento ácido por 15 segundos no máximo, para todos os cimentos testados.

\section{4 - DISCUSSĀO}

Atualmente o clínico tem à sua disposição para escolha, diferentes sistemas de materiais restauradores. $E$ de fundamental importância entender que a escolha entre estes sistemas depende da situaçāo clinica e da técnica a ser usada.

A última década tem sido marcada por mudanças radicais em procedimentos restauradores. Estas mudanças têm ocorrido, principalmente, através de avanços nos 
materiais odontológicos. Como exemplos desses materiais podemos citar os cimentos ionoméricos que estäo se projetando como bons restauradores dentro da Odontologia, mormente, quando $e$ indicado como base para restau raçōes de resina composta.

Entendemos que há muitas divergéncias de opiniōes e resultados de trabalhos de pesquisa dentre os autores citados abaixo.

Segundo McLEAN \{1988\} e PORTO NETO et al (1990) devemos limitar o tempo de condicionamento do cimento de ionómero de vidro em 15 segundos para evitar dissoluçăo da matriz e destruiçāo excessiva do cimento, além da penetraçäo e ácido nos túbulos dentinários. Da mesma forma, SMITH (1988) preconiza como tempo de condicionamento 30 segundos ou menos (procurando levar para um tempo de ataque menor possivel) e evidencia, ainda, que tanto faz o ácido fosfórico $37 \%$ IIquido ou gel, pois atuam com a mesma velocidade na superfície do ionómero.

GARCIA-GODOY \& MALONE (1986); MANGUM et al (1990); McLEAN et al (1985) e CHIN \& TYAS (1988) fazem observaçōes de que o cimento ionomérico deve ser condicionado para reter a resina composta, porque ela năo se unirå a uma superficie lisa.

Já SHETH et al (1989) diz que năo há diferença significativa entre a superflcie condicionada e não condicionada. Topograficamente, a superfície condicionada é quase tâo retentiva quanto uma superfície não condicionada. Estes resultados sugerem que não há necessidade de se condicionar o cimento de ionômero de vidro antes da restauração com resina composta. Da mesma forma, GARCIA-GODOY \& MALONE \{1986\} \& GARCIA-GODOY (1988) dizem que a base de ionômero de vidro condicionada não preveniu a infiltração sob restauraçōes de Classe $V$ com resina composta. Em contra-partida, MALDONADO, SWARTZ \& PHILLIPS (1978) revelam que um bom selamento das cavidades de Classe $V$ foi alcançado mesmo quando as margens estavam localizadas completamente ou parcialmente em cemento ou dentina.

Restaurar a cavidade com cimento ionomérico e deixar por 24 horas para que ocorra a "maturação" do ionómero de vidro, para depois restaurar com resina é o que idealiza MOUNT (1989a).

A espessura da camada com que esse ionômero deve permanecer no fundo da restauração, preconizada por McLEAN (1988) ê de $0,5 \mathrm{~mm}$ para que o ácido nāo cause danos à polpa.

Apesar de KAWAHARA; IMANISHI \& OSHIMA (1979) terem citado a baixa toxicidade dos cimentos ionoméricos, comparando-os com os cimentos de bxido de zinco e eugenol, dizendo que a reação pulpar que ocorre após a aplicação dos dois cimentos como protetores pulpares nāo é diferente, TOBIAS et al (1978) e SCHERER (1988) preconizam uma pequena camada de cimento de hidróxido de cálcio em cavidades consideradas profundas antes da acomodação do cimento de ionómero de vidro.

Muito embora nem todas as combinaçőes do cimento de ionômero de vidro e resinas compostas se unirâo com suficiente força para que se obtenha sucesso clinicamente, MOUNT (1989b) e MARTINS et al (1988) ressaltaram a importåncia da "simbiose" entre os dois materiais, associando as excelentes condiçōes estéticas das resinas compostas fotopolimerizáveis e os beneffcios do cimento ionomérico (adesấo à estrutura dental e liberação de flúor).

\section{5 - CONCLUSÄO}

Os cimentos de ionômero de vidro têm sido usados por mais de 10 anos e seu fndice de sucesso tem sido alto.

Enquanto os cimentos ionoméricos, sob muitas circunstâncias podem ser considerados como bons materiais restauradores, há situaçōes onde um reforço com resina composta ê necessária. Numa cavidade onde a resina composta é o material de escolha e uma ou mais margens estäo localizadas em dentina, o cimento de ionómero de vidro é o material mais indicado para se proteger a dentina e a polpa e para abastecer com flúor as margens da restauraçāo.

A combinação da resina composta com o cimento de ionômero de vidro é ideal, pois as vantagens de cada material podem ser aumentadas e suas limitaçöes minimizadas.

A técnica de "sandulche" (ionômero de vidro/resina composta) continua sendo um processo restaurador muito útil, pois associa as qualidades dos dois materiais e um passa a suprir as deficiências do outro.

SÁ, F.C. de; SÁ, R.S. de; SOUZA, J.B. de. Sandwich technique (glass-ionomer cement/composite resin) a Class $V$ restoration. Semina: Ci. Biol./Saúde, Londrina, v. 14, n. 2, p. 105-111, June 1993.

ABSTRACT: The authors based in a literature review, present some of the main advantages of glass-ionomer cements, as well as, report the results of their association with the composite resin, called Sandwich Technique. The authors also describe the clinical sequence of Class $V$ cavity preparation and restoration, using this technique.

KEY-WORDS: Sandwich Technique; Glass-jonomer cement; composite resin.

\section{REFERENCIAS BIBLIOGRAFICAS}

AMERICAN DENTAL ASSOCIATION. Stalus report on the glass Ionomer cements - Councll on Dental Material and Devices. J. Amer. Dent. Ass., v. 99, n. 2, p. 221-6, Aug. 1979.
BARATIERI, L.N. et al. Dentistica procedimenilos proventivas e restauradores. Rio de Janeiro: Quintessence, 1989. p.167-99. 
CHARBENEAU, G.T.; BOZELL, R.R. Clinical evaluation of a glass ionomer cement for restoration of cervical erosion. J. Amer. Dent Ass, v. 98, n. 6, p. 936-9, June 1979.

CHIN, Y.H.; TYAS, M.J. Adhesion of composite resin to etched glass ionomer cement. Aust. Dent J., v. 33, n. 2, p. 87-90, 1988.

GARCIA-GODOY, F. Glass ionomer material in Class II composite resin restorations: to etch or not to etch? Quintessence int, v. 19 , n. 3, p. 241-2, Mar. 1988.

GARCIA-GODOY, F.; MALONE, W.F.P. The effect of acid etching on two glass lonomer lining cements. Quintessence Int, v. 17, ก. 10 , p. $621-3$, Oct. 1986 .

KAWAHARA, H.; IMANISHI, Y.; OSHIMA, H. Blological evaluation on glass ionomer cement. J. Dent, Res, v. 58, n. 3, p. 1080-6, Mar. 1979.

MALDONADO, A.; SWARTZ, M.L.; PHILLIPS, R.W. An in vitro study of certains properties of glass lonomer cement. J. Arner. Dent Ass., v. 96, n. 5, p. 785-91, May 1978.

MANGUM, F.1. et al. Optimal etching time of glass ionomer cement for maximum bond of composite resin. J. Amer. Dent Ass, v. 120 , n. 5, p. 535-8, May 1990.

MARTINS, L.R.M. et al. Restauraçăo mista associando-se cimento ionomérico e resina composta. Rev. Odont USP., v. 2, n. 4, p. 229-32, out/dez. 1988.

McLEAN, J.W. et al. The use of glass ionomer cements in bonding composite resins to dentin. Bint Dent. J., v. 158, n. 11, p. 410-4, June 1985.

McLEAN, J.W. Glass ionomer cements. Brit. Dent, J., v. 164, n. 9, p. 293-300, May 1988.

MONDELLI, J. et al. Restauraçбes eststicas. Săo Paulo: Sarvier, $1984,190 p$.

MOUNT, G.J. Clinical requirements for a successful "Sandwich" dentin to glass ionomer cement to composite resin. AusL Dent J., v. 34, n. 3, p. 259-65, June 1989a.
MOUNT, G.J. The tensile strength of the unlon between varlous glass lonomer cements and various composite resins. Aust Dent $\}$, v. 34, n. 2, p. 136-46, April 1989b.

MOUNT, G.J. Restorations of eroded areas. J. Amer. Dent Ass., v. 120 , n. 1, p. 31-5, Jan. 1990.

POLETTO, L.T.A. Avaliaçđo da Resistencia de Uniăo entre Cimento de fonbmero de Vidro e Resina Composta. Bauru, 1988. 95p. Dissertaçăo (Mestrado) - Faculdade de Odontologla de Bauru, Universidade de Săo Paulo.

PORTO NETO, S.T. et al. Ataque ácido do ionômero de vidro. Rev. Gajcha Odont, v. 38, n. 5, p. 331-5, set./out. 1990.

POWIS, D.R. et al. Improved adhesion of a glass-ionomer cement to dentin and enamel. J. Dent Res, v. $61, n .12$, p. 1416-22, Dec. 1982.

SCHERER, W. Glass ionomer cements: Current status and apllcations. N. Y. St Dent J., v. 54, n. 7, p. 52-4, Aug/Sept. 1988.

SHETH, J.J. et al. Effect of etching glass ionomer cements on bond strength to composite resin. J. Dent Ros., v. 68 , n. 6, p. 1082-7, June 1989.

SMITH, G.E. Surface deterioration of glass-lonomer cement during acid-etching: an SEM evaluation. Oper. Dent, v. 13, n. 1, p. $3-7$, Winter 1988 .

SUZUKI, M.; JORDAN, R.E. Glass-ionomer-composite sandwich technique. J. Amer. Dent Ass., v. 120, n. 1, p. 55-7, Jan. 1990.

TOBIAS, R.S. et al. Pulpar response to a glass ionomer cement.

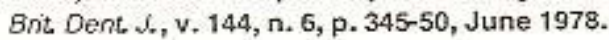

WILSON, A.D.; KENT, B.E. The glass ionomer cement, a new translucent dental filling material. J. A,ppl. Chem Biofechnol, v. 21 , p. 313-7, 1971.

WILSON, A.D.; KENT, B.E. A new translucent cement for dentistry: the glass ionomer cement. Brit. Dent J., v. 132, n. 4, p. 133-5, Feb. 1972.

Recebido para publicação em 18/11/1991

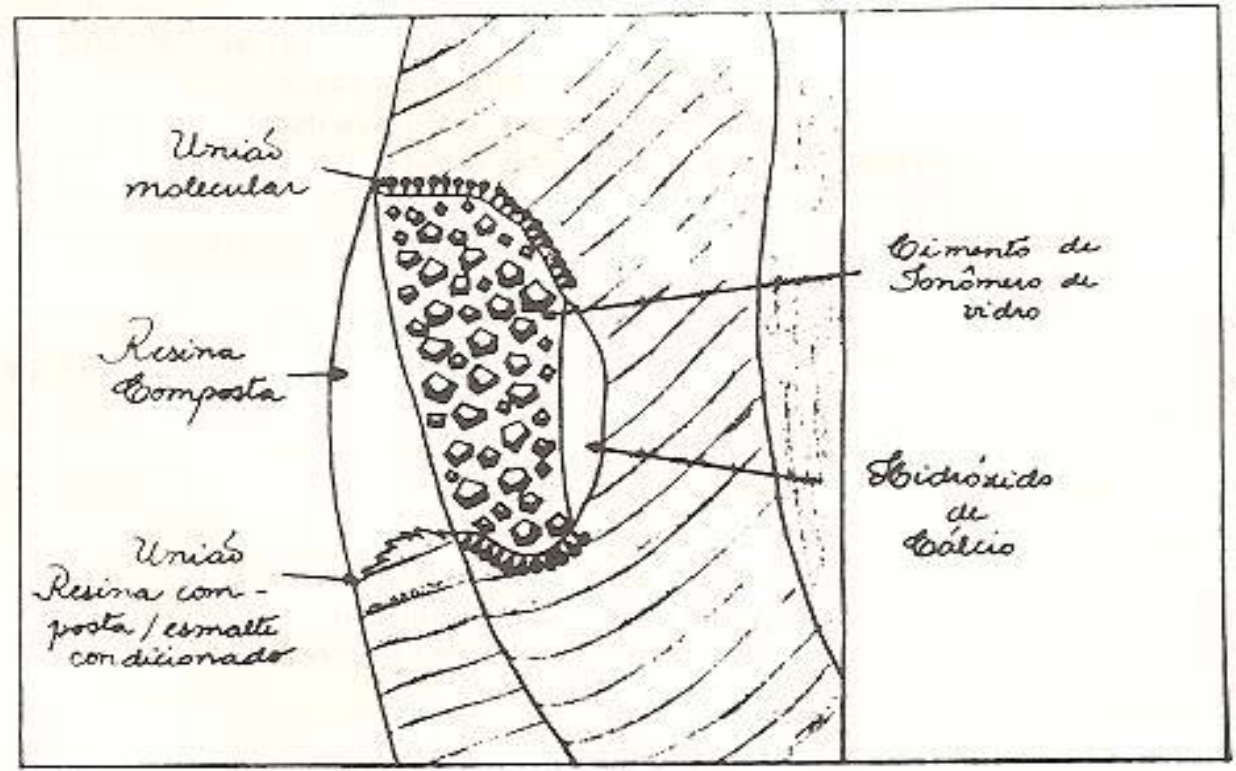

Semina, Ci. Biol/Saúde, v. 14, n. 2, p. 105-111, jun. 1993 